\title{
EFFECT OF ROOT CANAL GEOMETRY VERSUS DIFFERENT CORONAL RESTORATIONS ON THE STRENGTH OF ENDODONTICALLY TREATED TEETH
}

\author{
Shady Ali Hussein* and Ahmed A. Laithy**
}

\begin{abstract}
This study aimed to evaluate the combined effect of fiber post in different Root canal tapers. Sixty lower first premolar human extracted teeth had been used in this study, teeth were randomly divided into 3 equal groups $(n=20)$. Group I; where cleaning and shaping was done using Twisted File (TF) \#25 taper 0.04. Group II; where cleaning and shaping was done using Twisted File (TF) \#25 taper 0.06. Group III; where cleaning and shaping was done using Twisted File (TF) \#25 taper 0.08 . Each main group was randomly subdivided into 2 equal subgroups (10 each) according to the coronal restoration type. Subgroup A; where coronal cavities were filled with Composite core material Multicore Flow (Ivoclar Vivadent, Schaan, Liechtenstein) (MCF), Subgroup B; where the coronal cavities were restored with fiber reinforced composite posts (FRC) and MCF. The fracture resistance of all groups had been evaluated \& analyzed using Two-Way ANOVA. Results showed that 0.08 taper had a significant negative effect on the fracture resistance of teeth with and without post than 0.04 taper while other variants had no any statistically significant effect on the fracture resistance of the tested samples. It has been concluded that, under limitations of this study, the degree of taper of the root canal preparation only affects mechanical properties of the tooth when it increases more than 0.06 taper, while wether a post is used or not is of no use in class I conservative access cavity preparation of lower first premolar teeth.
\end{abstract}

\section{INTRODUCTION}

Endodontic success is a multifactorial procedure that depends upon multiple factors including canal preparation geometry and coronal restoration protocol. However, many debates had been made in the last decade on the significance of the coronal and apical seal with little focus on the influence of different root canal and coronal cavity preparation geometry.

A lot of tapers had been introduced in the market: $0.04,0.06$, and 0.08 in many systems and also progressive and uniform tapers. The significance of these tapers on the mechanical properties and survival rate of teeth was analyzed ${ }^{(1)}$. The twisted

* Lecturer at Endodontic Department, Faculty of Dentistry Ain Shams University

** Lecturer at Department of operative Dentistry, Faculty of Dentistry Ain Shams University 
NiTi files, which are files that were manufactured by twisting of NITI alloy in the R phase with triangular cross section that provided various instrument tapers such as 0.04, 0.06, 0.08 used either as single file technique or in crown down manner. As the instruments taper increases it removes more infected dentine which leads to cleaner canal walls.

Since endodontic treatment results in reduction of fracture resistance of teeth ${ }^{(2,3)}$. Therefore, one of the objectives of the coronal restorations is to reinforce the root canal and increase the resistance to root fracture. Alternative techniques had been introduced that incorporated the use of different composite core materials and fiber posts as a coronal restoration ${ }^{(4)}$.

Fiber-reinforced composite (FRC) posts luted with adhesive materials recently become more popular and frequently used because of their improved aesthetic and mechanical properties ${ }^{(5)}$.

The non-metallic fiber post has a modulus of elasticity similar to that of dentin that helps dentin in distribution of force along the root length and probably increases the fracture resistance of the tooth. ${ }^{(6,7)}$

A big controversy was found as to whether post rigidity and stress transmission has an effect on the fracture resistance and/or the failure mode of root canal treated teeth with posts cemented inside the root canals ${ }^{(8-10)}$

Previous researches were concerned with the effect of either the taper of instrument or the coronal restoration on the fracture resistance of root canal treated teeth ${ }^{(3,6,7,11,12)}$ and few literatures dealt with the multifunction complex that investigates the interaction and significance of both factors ${ }^{(1,2,13)}$. Thus, our research was conducted to evaluate the combined effect of different tapers of the root canal preparation geometry plus different alternatives of coronal restorations and the significance of using fiber reinforced composite posts on the fracture resistance of root canal treated lower first premolar teeth.

\section{MATERIAL AND METHODS}

For this study, 60 undamaged, extracted human mandibular first premolar teeth collected from teeth bank of the Faculty of Dentistry Ain Shams University were selected and checked to be free of caries and with approximately the same root length were selected. Each tooth was examined with a $4 \mathrm{X}$ binocular loupe (HEINE ${ }^{\circledR}$, Optotechnik, GmbH, Herrsching, Germany) to verify the absence of carious lesions, cracks, and microfractures. The coronal height and root length were limited to $8 \pm 1$ and $14 \pm 1$ $\mathrm{mm}$, respectively. Anatomic crowns were almost similar in dimensions, measuring $8 \pm 1 \mathrm{~mm}$ mesiodistally and $7 \pm 1 \mathrm{~mm}$ bucco-lingually, at the cementoenamel junction. Selected teeth were then stored in distilled water at $37^{\circ} \mathrm{C}$ during the experiment. Access cavities were done using diamond stone with round end (Mani). Stainless steel k-file (\#15 taper 0.02 ) that was introduced in the root canals until its tip is visible at the apical foramen. Working length was determined visually by subtracting $1 \mathrm{~mm}$ from the visually detected length.

Teeth were then randomly divided into three equal groups $(n=20)$. Group I; where cleaning and shaping was done using Twisted File (Sybron Endo rotary NiTi TF, Mexico) \#25 taper 0.04 in a crown down manner until reaching the working length. Group II; where cleaning and shaping was done using Twisted File (Sybron Endo rotary NiTi TF, Mexico) \#25 taper 0.06 in a crown down manner until reaching the working length. Group III; where cleaning and shaping was done using Twisted File (Sybron Endo rotary NiTi TF, Mexico) \#25 taper 0.08 in a crown down manner until reaching the working length. In all groups, root canals were flushed with $5 \mathrm{~mm}$ freshly prepared $2.5 \%$ sodium hypochlorite solution during instrumentation to flush away any dentin debris and to avoid canal blockage.

Canals were then obturated using thermoplasticized continuous wave technique in each test group with the corresponding taper of the master cone (META BIOMED Gutta percha) where it 
was sealed to canal dentin using eugenol-free root canal sealing material (AH Plus, Dentsply, De Trey, Germany). Teeth were then stored in $100 \%$ humidity for two weeks for the sealer setting.

Following obturation of the cleaned and shaped root canals, each main group was randomly subdivided into two equal smaller subgroups (10 each) according to the coronal restoration type. Subgroup A; where the coronal cavities were filled only with core material, Multicore Flow (Ivoclar Vivadent, Schaan, Liechtenstein) (MCF) according to manufacturer's instructions and was injected into cavity by the aid of a specific gun. However, for Subgroup B samples, a drilling for the fiberreinforced translucent glass fiber cylindro-conical composite post [I-Post] (ITENA Dentolic, France) of $1.2 \mathrm{~mm}$ size was done using ITENA drill (ITENA Dentolic, France). The selected FRC posts were tried-in and fitted inside the root canals and then cementation of the posts was done by using a dual curing luting resin (Variolink II, Ivoclar Vivadent), according to the manufacturer's instructions..

Roots of the tested samples were coated with a single layer of low viscosity rubber impression material (Imprint II, 3M ESPE, St. Paul, MN) to mimic the natural periodontal ligament. The coated roots were then embedded into acrylic resin blocks attempting to conduct the fracture resistance test.
Regarding fracture resistance testing, the buccal cusps of all restored sample teeth were then compressively stressed (at $135^{\circ}$ inclination to the long axes of the roots) till fracture by the aid of a round end rod on a universal testing machine (LLOYD Universal Testing Machine, LR 5K, Ametek / LLOYD Instruments, Fareham, UK) running at a crosshead speed of $1 \mathrm{~mm} / \mathrm{min}$.

The maximum load at failure was then recorded for each specimen and the collected data were statistically analyzed using both ANOVA and Tukey's comparisons at a $=0.05$ to determine the significance of the differences detected between subgroups.

\section{RESULTS}

Means \pm standard deviations (SD) for the effect of type of coronal restoration and taper on the fracture resistance of teeth are presented in Table (1). Two-Way ANOVA showed that the taper had a significant effect on the fracture resistance. On the other hand, neither the taper nor the interaction of the independent variables (taper and coronal restoration) had a significant effect on the fracture strength of teeth. Group III has statistically lower fracture resistance than Group I in both subgroups $(\mathrm{P}=0.026)$, while all other was not statistically significant.

TABLE (1) Means \pm Standard Deviations (SD) and coefficient of variation (CV \%) for the effect of taper and cavity design of fracture strength of teeth.

\begin{tabular}{|c|c|c|c|}
\hline \multirow{2}{*}{ Taper } & Subgroup A & Subgroup B & \multirow{2}{*}{ P Value } \\
\hline & Mean \pm SD & Mean \pm SD & \\
\hline Group I & $\begin{array}{c}331.22 \pm 59.3 \mathrm{a} \\
(17.9 \%)\end{array}$ & $\begin{array}{c}344.52 \pm 40.71 \mathrm{a} \\
(11.81 \%)\end{array}$ & 0.522 \\
\hline Group II & $\begin{array}{c}297.5 \pm 40.41 \mathrm{ab} \\
(13.58 \%)\end{array}$ & $\begin{array}{c}310.96 \pm 36.37 \mathrm{ab} \\
(11.69 \%)\end{array}$ & 0.135 \\
\hline Group III & $\begin{array}{c}251.25 \pm 28.37 b \\
(11.29 \%)\end{array}$ & $\begin{array}{c}276.22 \pm 72.15 \mathrm{~b} \\
(26.12 \%)\end{array}$ & 0.026 \\
\hline
\end{tabular}

$P=$ Probability for the effect of taper. Means with the same letter within each column are not significantly different at $p \leq 0.05$. 


\section{DISCUSSION}

Both endodontic and restorative treatment affect the mechanical properties of the tooth structure as both remove dentin during the procedures which cause weakening of the tooth structure ${ }^{(3,11,12)}$, such treatment options may lead to tooth fracture and finally tooth $\operatorname{loss}^{(14-17)}$. Therefore, the aim of this study was to evaluate the interaction between these two procedures and their combined effect on the fracture resistance of tooth structure.

In most of literature, the measurement of the fracture resistance was done after cutting of the crown until the cemento-enamel junction (18). While in this study, the crown was left intact with a conservative access cavity preparation so as to evaluate the effect of dentin removal in the apical part of the tooth combined with the use of nonmetallic post.

Consequently, to evaluate if the presence of a shelter of enough amount of tooth structure can compensate for the apical dentin lost during increasingly flared root canal geometry or not and to what extent this shelter may compensate for apical dentin removal. Also, to evaluate whether this weakening effect if found can be compensated with a non-metallic post with comparable modulus of elasticity of dentin or not.

In this study, it was found that the continuous increase of taper causes less fracture resistance but there was no statistically significant difference between each subsequent group but between Group I (0.04 taper) and Group III (0.08 taper). There was statistical difference in agreement with the Sabeti M. et al ${ }^{(1)}$ which may be because of the loss of the tooth structure significantly between the two tapers and the major alteration of the canal anatomy of the rigid large taper file ${ }^{(3,19)}$. Propagation of microcracks created during root canal shaping process with occlusal forces causes root fracture ${ }^{(20)}$. therefore, suggestion is that the decrease of fracture resistance with the .08 taper in this study might be associated with the greater number of craze lines and the greater degree of imposed stress in root dentin. Moreover, our findings corroborated the results of a previous study that reported that preparation with larger taper instruments significantly weakened the roots. Also, Zandbiglari et al, $2006^{(19)}$ suggested that this result was probably caused by the greater amount of dentin removed with larger tapering instruments compared with common taper hand files.

The use of non-metallic fiber post did not support the tooth significantly in comparison to the large amount of remaining tooth structure left. Unlike Makade et al, 2011 and others ${ }^{(5,21,22)}$, who found that presence of post statistically significant than control tooth filled with composite only, probably due to that he decoronated the tooth and build the core with free part without tooth structure while in this study the crown is intact, so the remaining amount of tooth structure is large in relation to area of post and core so no significant difference in fracture resistance was found.

A clinically randomized trial in vivo with long term follow up is advised for more evidence-based data.

\section{CONCLUSIONS}

It has been concluded that, with the limitation of this study the taper of the preparation only affects mechanical properties of the tooth when it increases more than 0.06 , while the post is of no use in class I conservative access cavity preparation of lower first premolar.

\section{REFERENCES}

1. Sabeti M, Kazem M, Dianat O, Bahrololumi N., Beglou K., Rahimipour k., and Dehnavi F. Impact of Access Cavity Design and Root Canal Taper on Fracture Resistance of Endodontically Treated Teeth: An Ex Vivo Investigation. J Endod 2018; 44:1402-6.

2. Al Amri MD, Al-Johany S, Sherfudhin H, et al. Fracture resistance of endodontically treated mandibular first 
molars with conservative access cavity and different restorative techniques: an in vitro study. Aust Endod J 2016; 42:124-31.

3. Lang H, Korkmaz Y, Schneider K, Raab W-M. Impact of endodontic treatments on the rigidity of the root. J Dent Res 2006; 85:364-8.

4. Assif D, Nissan J, Gafni Y, Gordon M. Assessment of the resistance to fracture of endodontically treated molars restored with amalgam. J Prosthet Dent 2003;89: 462-5.

5. Cobankara FK, Unlu N, Cetin AR, Ozkan HB. The effect of different restoration techniques on the fracture resistance of endodontically-treated molars. Oper Dent 2008; 33:526-33.

6. Toure B, Faye B, Kane AW, et al. Analysis of reasons for extraction of endodontically treated teeth: a prospective study. J Endod 2011; 37:1512-5.

7. Zandbiglari T, Davids H, Sch€afer E. Influence of instrument taper on the resistance to fracture of endodontically treated roots. Oral Surg Oral Med Oral Pathol Oral Radiol Endod 2006; 101:126-31.

8. Abo El-Ela O., Atta O., El-Mowafy O. Fracture Resistance of Anterior Teeth Restored with a Novel Nonmetallic Post. JCDA 2008; 74:441-441e.

9. Alsamadani K., Abd aziz E., Gad E. Influence of Different Restorative Techniques on the Strength of Endodontically Treated Weakened Roots

10. L. Bu “ ttel, G. Krastl, H. Lorch, M. Naumann, N. U. Zitzmann and R. Weiger. Influence of post fit and post length on fracture resistance. Int Endod J 2009; 42:47-53.

11. K. Bitter, H. Meyer-Lueckel , N. Fotiadis, U. BlunckK, Neumann A. M. Kielbassa \& S. Paris. Influence of endodontic treatment, post insertion, and ceramic restoration on the fracture resistance of maxillary premolars. Int En$\operatorname{dod} \mathrm{J} 2010 ; 43: 469-477$.

12. Heydecke G, Butz F, Hussein A, Strub JR Fracture strength after dynamic loading of endodontically treated teeth restored with different post-and-core systems. Journal of Prosthetic Dentistry 2002; 87:438-45.
13. Isidor $\mathrm{F}$, Odman $\mathrm{P}$, Brondum $\mathrm{K}$ Intermittent loading of teeth restored using prefabricated carbon fiber posts. International Journal of Prosthodontics 1996;9:131-6.

14. Akkayan B, Gulmez T Resistance to fracture of endodontically treated teeth restored with different post systems. Journal of Prosthetic Dentistry 2002 ;87: 431-7.

15. Fokkinga WA, Kreulen CM, Vallittu PK, Creugers NH A structured analysis of in vitro failure loads and failure modes of fiber, metal, and ceramic post-and-core systems. International Journal of Prosthodontics 2004;17:476-82.

16. Makade C., Meshram G., Warhadpande M., Patil P. A comparative evaluation of fracture resistance of endodontically treated teeth restored with different post core systems - an in-vitro-study. J Adv Prosthodont 2011;3:90-5

17. Adorno CG, Yoshioka T, Jindan P, et al. The effect of endodontic procedures on apical crack initiation and propagation ex vivo. Int Endod J 2013; 46:763-8.

18. S,u“kran Bolay, Elif O”ztu“ rk, Behram Tuncel, Atilla Er$\tan$. Fracture resistance of endodontically treated teeth restored with or without post systems. jds 2012; 7, 148-153.

19. Shukri B., Al-Zaka I., Mustafa A., Aziz M., Rajab M. Evaluation the Fracture Resistance of Endodontically Treated Teeth Restored With Different Post and Core Materials. Tikrit Journal for Dental Sciences 2012; 2:110-116.

20. Clark D, Khademi J. Modern molar endodontic access and directed dentin conservation. Dent Clin North Am 2010; 54:249-73.

21. Shahrbaf S, Mirzakouchaki B, Oskoui SS, Kahnamoui MA. The effect of marginal ridge thickness on the fracture resistance of endodontically-treated, composite restored maxillary premolars. Oper Dent 2007; 32:285-90.

22. Tzimpoulas NE, Alisafis MG, Tzanetakis GN, Kontakiotis EG. A prospective study of the extractionandretention incidenceof endodonticallytreated teeth with uncertain prognosis after endodontic referral. J Endod 2012; 38:1326-9. 